\title{
Complications of Cosmetic Tattoos
}

\section{Christa De Cuyper}

Department of Dermatology, AZ Sint-Jan, Brugge, Belgium

\begin{abstract}
Cosmetic tattoos, which are better known as permanent make-up, have become popular in the last decades. This same procedure can be used to camouflage pathological skin conditions, to mask scars and to complete the aesthetic results of plastic and reconstructive surgeries. The risks and complications of tattooing procedures include infections and allergic reactions. Scarring can occur. Fanning and fading of the colorants and dissatisfaction with colour and shape are not unusual. Different lasers can offer solutions for the removal of unwanted cosmetic tattoos, but complications due to the laser treatment, such as paradoxical darkening and scarring, can arise.
\end{abstract}

๑) 2015 S. Karger AG, Basel

\section{Introduction}

Since the 19th century, several reports have illustrated the medical applications of tattooing for aesthetic purposes [1-3]. The introduction of eyelid tattooing in 1984 represented a new start of facial cosmetic tattooing [4]. The main pur- pose of cosmetic tattooing is to enhance natural beauty and to increase physical appeal. The majority of subjects choose cosmetic tattooing because it offers an easy alternative to conventional make-up.

\section{Technique and Materials}

Cosmetic tattooing, which is also called micropigmentation, is usually performed with an electrical tattoo device or a tattoo pen with a rotating or oscillating disposable needle (fig. 1). Small droplets of specific permanent make-up (PMU) tattoo ink are implanted into the superficial layer of the dermis in contrast with decorative tattooing, in which the deposition of pigment occurs deeper within the dermis. Some PMU devices are programmed for specific indications. A good knowledge of anatomy is important to ensure for good results. Singleuse ink caps are advised, and registration of the colours used can be helpful for later corrections. Prepared inks are available on the market, but some 
Fig. 1. Tattoo (PMU) device.

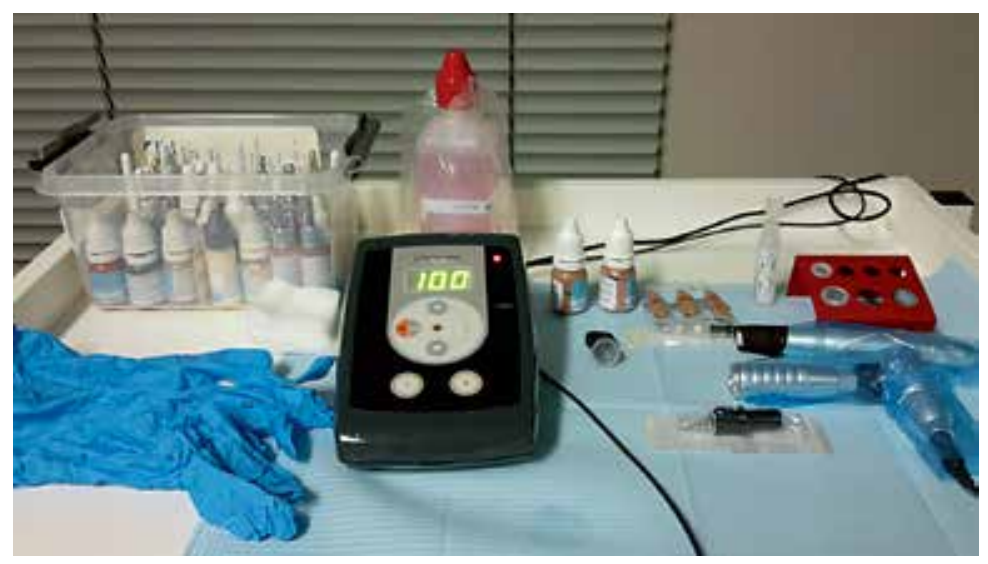

professionals make their own mixtures to obtain optimal colours to match a client's favourite makeup. The elimination of pigment can occur during the first days of healing. After healing, the remaining pigment particles are stored in dermal macrophages and fibroblasts. The nature of the material used and the level of implantation influence the quality and stability of the results. Because the level of application of PMU is more superficial than that in decorative tattooing, the spontaneous elimination of the colorant and fading may occur within years.

\section{Indications}

PMU is an excellent replacement for conventional make-up and a practical solution for people with an active lifestyle because it is time saving and always looks perfect and fresh [5] (table 1). Some choose this procedure because they have a physical impairment complicating the application of temporary make-up. Eyeliner or blepharo-pigmentation, lip liner and eyebrow colouring are very popular. When it is properly applied by an experienced technician, PMU can be more natural and realistic in appearance than conventional make-up. Medical indications include corneal reconstruction and nipple-areola complex
Table 1. Indications for cosmetic tattoos/PMU

Replacement of conventional make-up

Medical reasons:

- patients with allergies to conventional make-up

- disabled persons (arthrosis-arthritis)

- trembling hands (Parkinson disease)

- poor vision/contact lenses

- hay fever

Camouflage and correction of:

- scars (accidental and surgical)

- nipple-areola complex reconstruction

- birthmarks

- alopecia/vitiligo

reconstruction after breast reduction or breast cancer surgery [3] (fig. 2). Tattooing may help to camouflage scars, birth marks, vitiligo and alopecia and also offers a solution for patients with allergies to conventional cosmetics [6] (fig. 3).

\section{Risks and Complications}

Tattooing in general is not without risks [7] (table 2). The major risk of complications and dissatisfaction is caused by the performing of the 


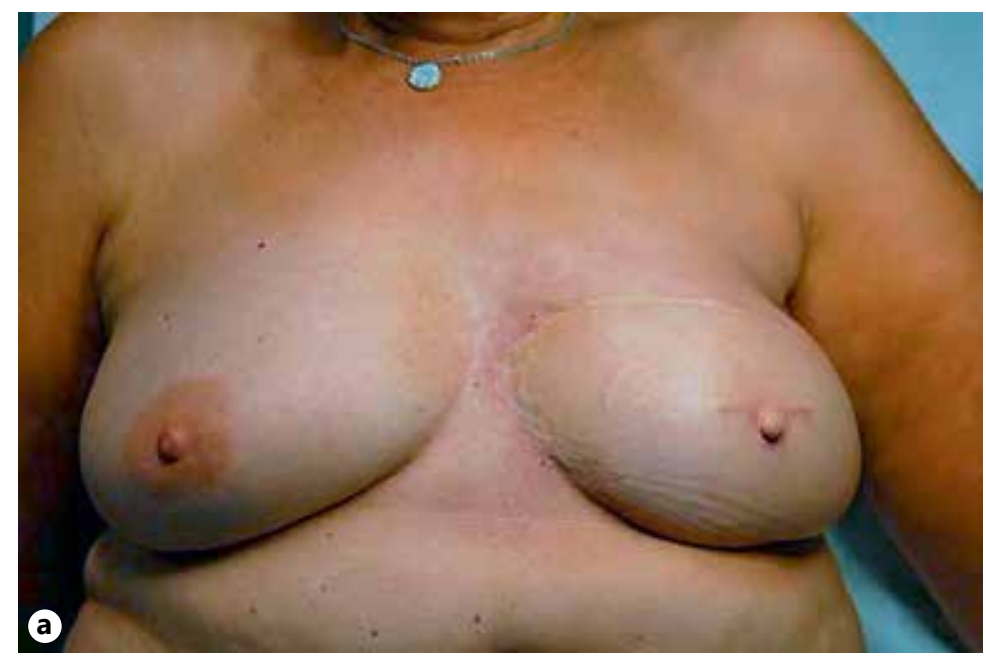

Fig. 2. Nipple-areola complex reconstruction before (a) and after (b) (courtesy of Rika Dubelloy).

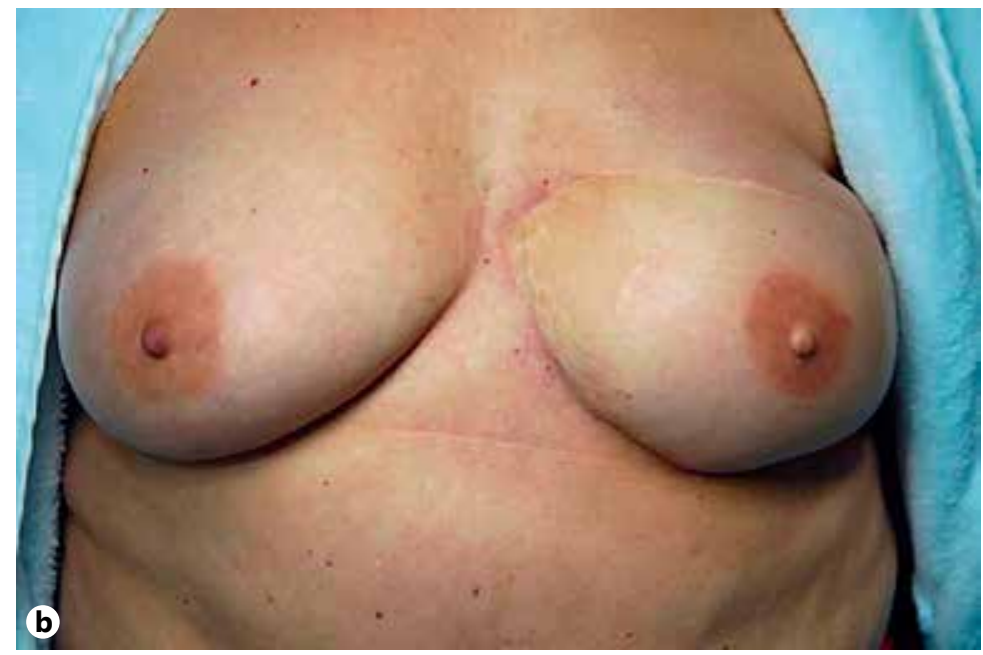

procedure by an inexperienced person under poor hygienic circumstances and with materials of dubious origin. Side effects can be related to the procedure and the aftercare and also to the instruments and compositions of the inks used [8]. Short-term side effects include mild swelling and crusting, which are usually dealt with by clients and tattooists and not reported. However, when more important problems, such as infections and allergic reactions, arise, medical advice is required [9]. The US Food and Drug Administration (FDA) registered only 5 reports of adverse reactions associated with PMU from 1988 to 2003. Beginning in 2003, the FDA received more than 150 reports of adverse events occurring in persons who had undergone PMU procedures, including some severe and longterm disfiguring complications. Symptom durations have ranged from 5.5 months to more than 3 years. More adverse reactions have been linked with a specific product line, suggesting an increased risk associated with the use of these inks. This product line was recalled from the market in September 2004 [10]. 


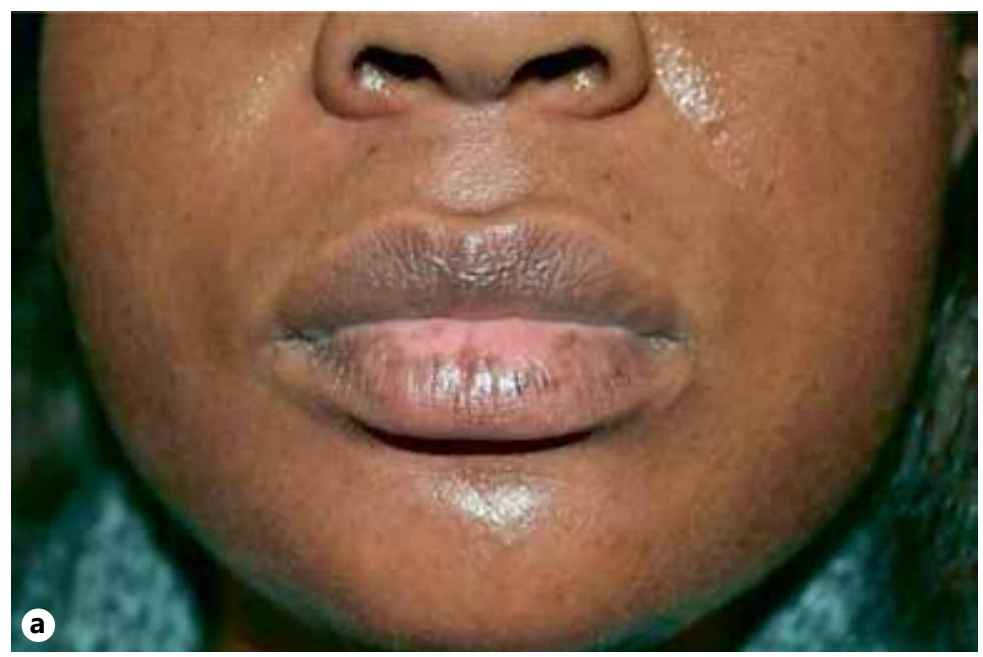

Fig. 3. Vitiligo lip correction before (a) and after (b) (courtesy of Rika Dubelloy and Finishing Touches).

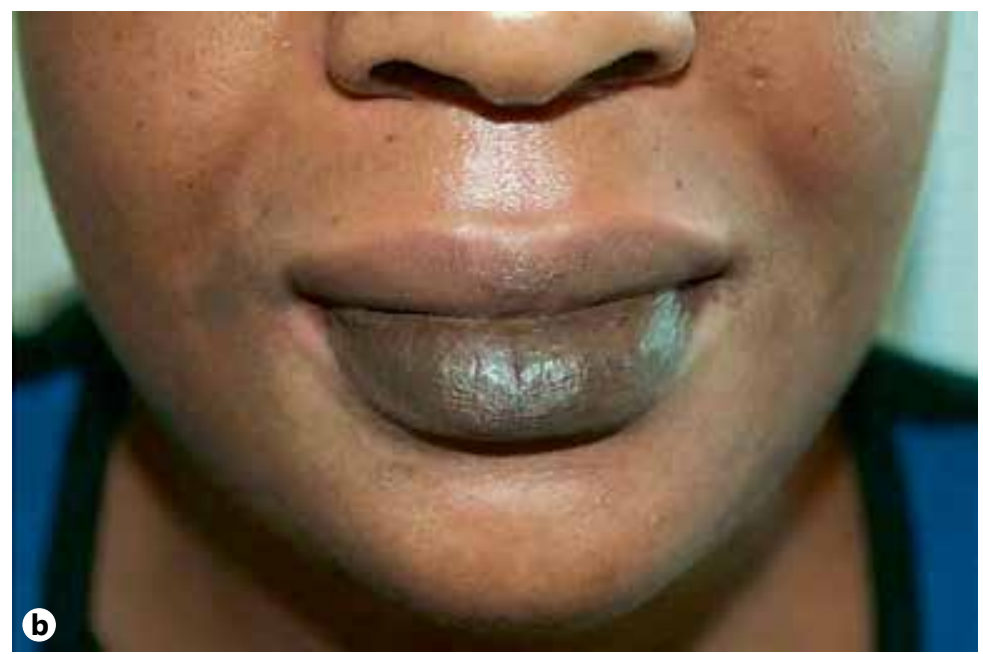

\section{Infections}

When performed under correct hygienic conditions and with sterile materials, the occurrence of bacterial infection is rare. Inks can be contaminated before or after bottles are opened [11]. In recent years, several cases of atypical mycobacterial infections in decorative and cosmetic tattoos have been reported [12-14]. Histological and microbiological confirmations are helpful to exclude other granulomatous conditions, such as sarcoidosis, foreign body reactions and allergic granulomatous manifestations and to identify the responsible pathogen [15-17]. Source identification is a very important issue [12]. The registration of inks in a client's file can help to identify contaminated batches. Recently, a voluntary recall of tattoo ink, tattoo needles and tattoo kits distributed by White \& Blue Lion due to pathogenic bacterial contamination was announced by the FDA [18].

Viral and mycotic infections are extremely rare. Unsterile equipment and needles can transmit all types of blood-borne infections, such as 
Table 2. Complications of tattooing

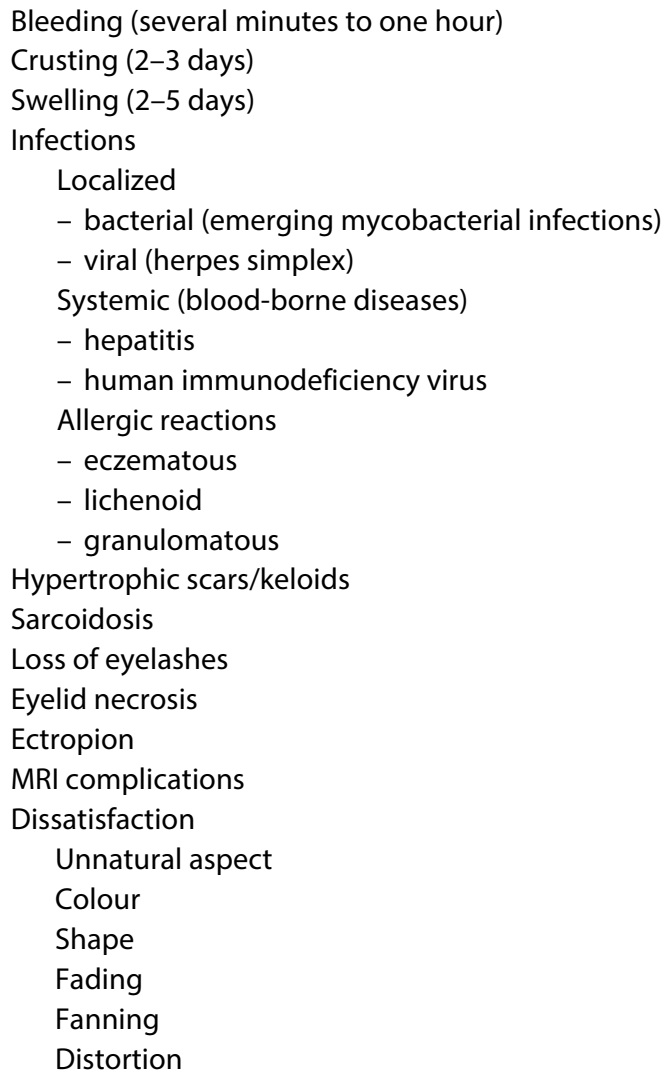

hepatitis and human immunodeficiency virus. Preventive screening of body art practitioners and vaccination for hepatitis B are advised. The risk of herpes simplex reactivation on the lips induced by the procedure should be taken into account (fig. 4).

\section{Allergy}

The pigments and dyes used in tattoo and PMU inks are relatively inert and are usually well tolerated. Allergic reactions to colorants are rare, but when they occur, they may be particularly troublesome because the pigments can be difficult to remove. The majority of allergic reactions that have been reported have been related to red inks. Hypersensitivity reactions can have different clinical and histological presentations, including lichenoid, psoriasiform, eczematous, lymphomatoid and granulomatous reactions. Clinical aspects and histopathologies are often suggestive of a delayed-type allergy (fig. 5). Skin testing, however, has produced very disappointing results [19]. In vivo haptenisation of the colorant could be the explanation [20]. Contact dermatitis to other ingredients and additives or to the materials used during and after the procedure, such as topical antibiotics, can also occur. Photosensitivity of tattoos is probably the reason why more adverse reactions have been reported in tattoos in sun-exposed areas, such as the hands and face $[7,21]$.

\section{Other Complications}

In general, cosmetic tattooing causes little discomfort, and side effects are rare, although complications, such as eyelid necrosis, the loss of eyelashes, secondary cicatricial ectropion, hypertrophic scars and keloids, have been reported $[1,13]$. To reduce the risk of ocular injury, protective eye shields can be used during the procedure [22]. The possibility of the Koebner effect in patients with a pre-existing skin disorder, such as psoriasis, must be considered. There have been reports of people with tattoos and permanent make-up experiencing swelling or burning in the tattooed areas when undergoing magnetic resonance imaging. This has been reported only rarely and has not been associated with any lasting effects. Pigments may also interfere with the quality of the image, particularly in the eye area [23]. The extremely rare association of skin cancer with tattoos in general and with PMU in particular seems to be a coincidence rather than a causative relation $[24,25]$. 
Fig. 4. Herpes simplex of the lip (courtesy of Jørgen Serup).

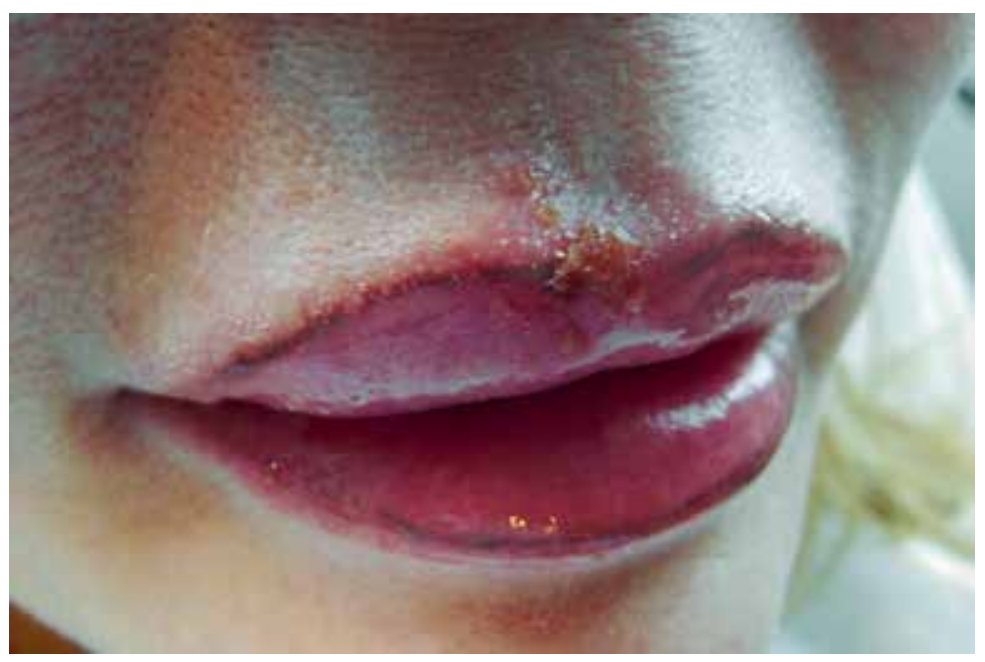

Fig. 5. Allergic reaction of PMU lip liner (courtesy of Jørgen Serup).

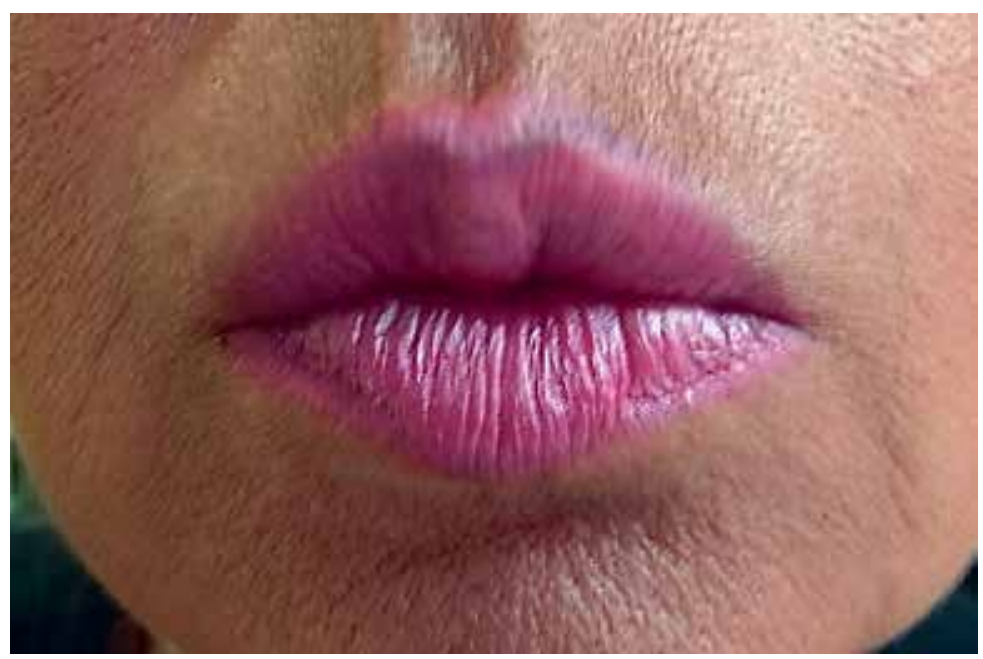

\section{Dissatisfaction}

Some people have unrealistic expectations and are unhappy with their cosmetic results. Customers should be informed that tissue augmentation, botulin toxin injection and plastic surgery of the face can change the appearance and lead to the distortion of PMU.

The most common complications and patient dissatisfaction, however, result from the misap- plication of colorants, pigment migration and pigment fanning $[5,26]$. In these situations, the advantage of being permanent becomes the greatest disadvantage (fig. 6).

\section{Treatment of Complications}

Medical complications should be treated with specific case-related measures. Localised bacterial in- 
Fig. 6. Dissatisfaction. Unnatural aspect of eyeliner and fanning of the pigment.
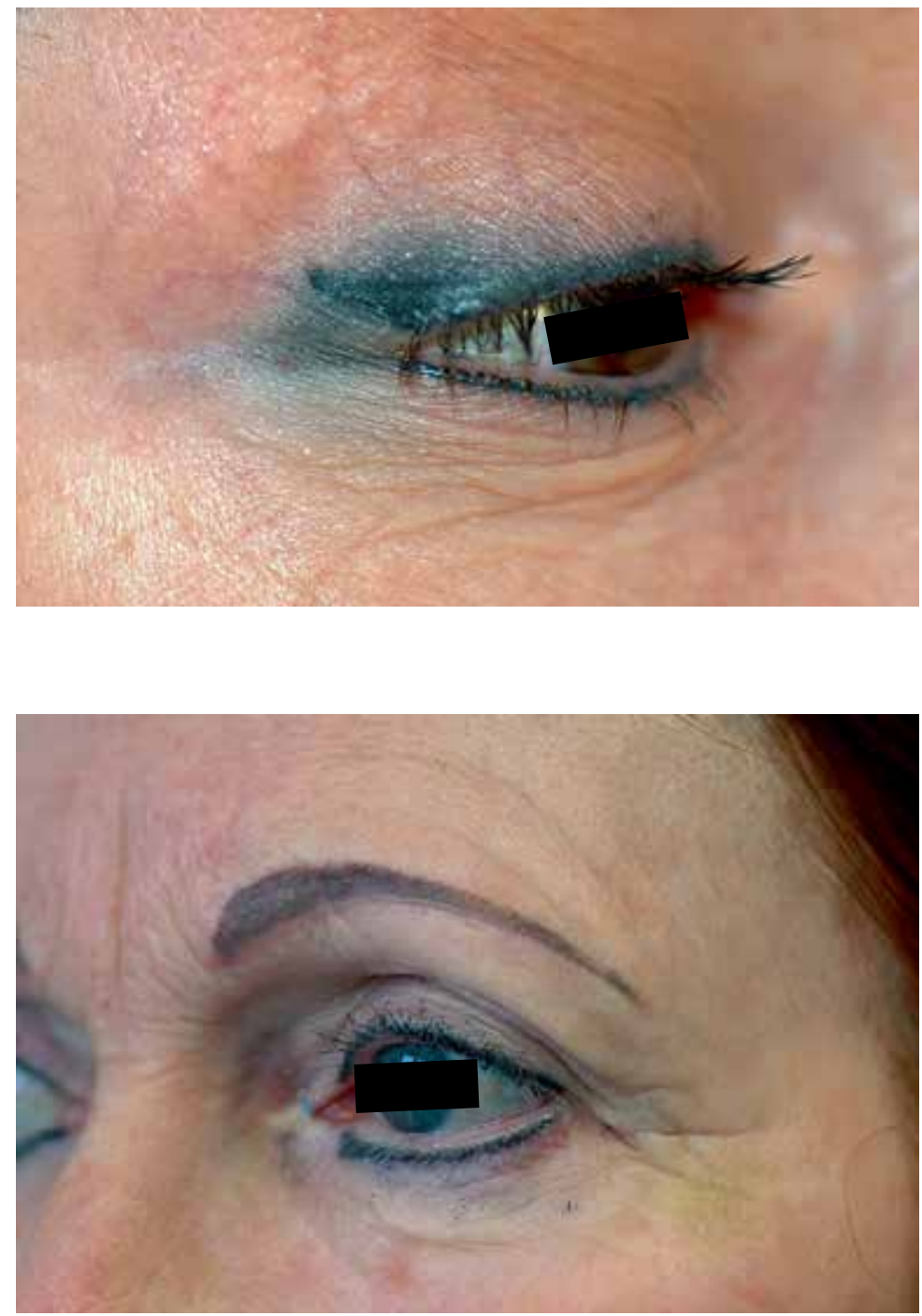

Fig. 7. Dissatisfaction with the colour and shape of eyebrow PMU. fections require antiseptic or antibiotic treatment to minimise the risk of scarring. For severe infections, systemic antibiotics are needed. Allergic manifestations can be treated with topical applications or infiltration with corticosteroids [19]. The combination of intralesional injections of steroids and 5-fluorouracil has been used to treat foreign body reactions and may be considered. The resolution of a lip-enhancing tattoo reaction by topical tacrolimus treatment has been documented by
Wylie [27]. Granulomatous reactions are often problematic because the causative material is difficult to remove. Systemic therapy with corticosteroids and cyclosporine can be used but rarely provides satisfactory results. Chronic reactions sometimes require more invasive techniques, including surgical dermabrasion or pigment removal with ablative lasers [28-30]. Objectionable tattoos can be camouflaged with conventional make-up. Over time, most cosmetic tattoos fade spontaneously. 
Fig. 8. Results of partial clearing after treatment with a combination of a QS Nd-Yag 532 and QS Nd-Yag 1064 laser.
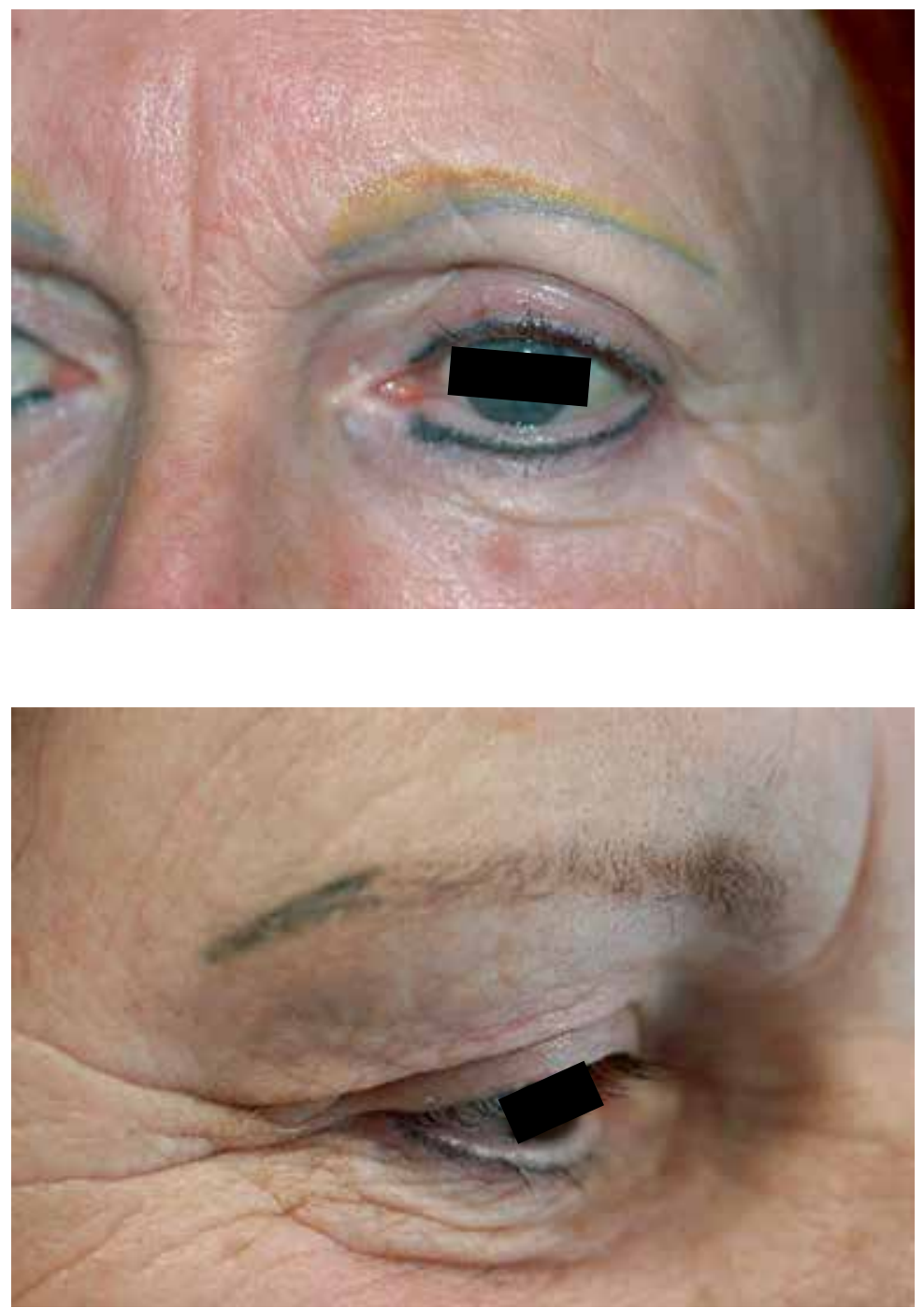

Fig. 9. Darkening of $P M U$ after treatment with a QS Nd-Yag 532 laser. techniques, such as surgery and dermabrasion, are available but have risks of scarring and residual textural and pigmentary changes. The best cosmetic results can be obtained using pigment lasers, but even this technique has its risks, and the complete clearing of the tattoo cannot be guaranteed [33] (fig. 7, 8). Flesh tones and red tattoos containing ferric oxide may show immediate darkening when treated with short pulse lasers [33-36]. This is probably caused by the reduction of red-brown-coloured ferric oxide to black-coloured 
ferrous oxide (fig. 9). In our experience, the dark colour can often be subsequently removed using another appropriate wavelength [5]. Paradoxical darkening can also occur in tattoos containing titanium dioxide. The topical application of perfluorodecalin may be helpful for the reduction of laserinduced whitening, allowing for more laser passes per treatment session and improving the outcome [37]. In some recalcitrant cases, dermabrasion techniques with a carbon dioxide laser can offer a solution [28]. Pico-second lasers could be more effective but are still under investigation.

\section{Conclusion}

Although cosmetic tattooing is a common and popular procedure and is usually well tolerated, complications can occur. One problem associated with this procedure lies in the lack of uniform legislation worldwide and the lack of control of the production of the substances used. The availability of correct information about the associated risks as well as the performance of the procedure by a well-trained professional can minimise complications and dissatisfaction.

\section{References}

1 Vassileva S, Hristakieva E: Medical applications of tattooing. Clinics Dermatol 2007;25:367-374.

-2 Van der Velden EM, Defrancq J, Ijselmuiden OE: Review: dermatography: a review of 15 years of clinical applications in surgery. Int J Cosm Surgery Aest Dermatol 2001;3:151-159.

-3 Fahradi J, Maksvytyte GK, Schaefer DJ, et al: Reconstruction of the nipple-areola complex: an update. J Plast Reconstr Aesthet Surg 2006;59:40-53.

14 Angres G: Eyeliner implants: a new cosmetic procedure. Plast Reconstr Surg 1984;73:833-836.

5 De Cuyper C: Permanent makeup: indications and complications. Clin Dermatol 2008;26:30-34.

6 Seité S, Deshayes P, Dréno B, et al: Inter est of corrective makeup in the management of patients in dermatology. Clin Cosm Invest Dermatol 2012;5:123-128.

7 Wenzel SM, Rittmann I, Landthaler M, et al: Adverse reactions after tattooing: review of the literature and comparison to results of a survey. Dermatology 2013;226:138-147.

-8 Pérez-Cotapos ML, De Cuyper C, Cossio L: Tattooing and scarring: technique and complications; in De Cuyper C, PérezCotapos ML (eds): Dermatologic Complications with Body Art: Tattoos, Piercings and Permanent Make-Up. Berlin, Springer Heidelberg, 2010, pp 29-41.

$\checkmark 9$ Ortiz AE, Alster TS: Rising concern over cosmetic tattoos. Dermatol Surg 2012; 38:424-429.
0 Straetemans M, Katz LM, Belson M: Adverse reactions after permanentmakeup procedures. N Engl J Med 2007; 356:26.

$>11$ Hoegsberg T, Saunte DM, FrimodtMøller N, et al: Microbial status and product labelling of 58 original tattoo inks. J Eur Acad Dermatol Venereol 2013;27:73-80.

$\checkmark 12$ Kennedy BS, Bedard B, Younge M, et al: Outbreak of Mycobacterium chelonae infection associated with tattoo ink. $\mathrm{N}$ Engl J Med 2012;367:1020-1024.

13 Wollina U: Nodular skin reactions in eyebrow permanent makeup: two case reports and an infection with Mycobacterium haemophylum. J Cosmet Dermatol 2011;10:235-239.

14 Guilieri S, Morisod B, Edney T, et al: Outbreak of Mycobacterium haemophilum infections after permanent makeup of the eyebrows. Clin Infect Dis 2011;52: 488-491.

15 Antonovich DD, Callen JP: Development of sarcoidosis in cosmetic tattoos. Arch Dermatol 2005;141:869-872.

16 Yesudian PD, Azurdia RM: Scar sarcoidosis following tattooing of the lips treated with mepacrine. Clin Exp Dermatol 2004;29:552-554.

17 Baumgarter M, Feldmann R, Steiner A: Sarcoidal granulomas in a cosmetic tattoo in association with pulmonary sarcoidosis. J Dtsch Dermatol Ges 2010;9: 900-902.

18 Specialty Pharma Association. Industry News. http://www.specialtypharma.org/ news.asp?id=356157.
19 Wenzel SM, Welzel J, Hafner C, et al: Permanent make-up colorants may cause severe skin reactions. Contact Dermatitis 2010;63:223-227.

20 Serup J, Hutton Carlsen K: Patch test study of 90 patients with tattoo reactions: negative outcome of allergy patch tests to baseline batteries and culprit inks suggest allergen(s) are generated in the skin through haptenization. Contact Dermatitis 2014;71:255-263.

21 Jaeger C, Hartschuh W, Jappe U: Sunlightinduced granulomatous reaction to permanent lip liner. Hautarzt 2005;56:63-65.

$\checkmark 22$ Konuk O, Evereklioglu C, Handur A, et al: Protective eyeshield can prevent corneal trauma during micropigmentation for permanent eyeliner. J Eur Acad Dermatol 2004;18:642-643.

23 Tope WD, Shellock FG: Magnetic resonance imaging and permanent cosmetics (tattoos): survey of complications and adverse events. J Magn Reson Imaging 2002;15:180-184.

24 Kluger N, Koljonen V: Tattoos, inks, and cancer. Lancet Oncol 2012;13:e161-e168.

25 Ortiz A, Yamauchi PS: Rapidly growing squamous cell carcinoma from permanent makeup tattoo. J Am Acad Dermatol 2009;60:1073-1074.

26 Lee IW, Ahn SK, Choi EH, et al: Complications of eyelash and eyebrow tattooing: reports of 2 cases of pigment fanning. Cutis 2001;68:53-55.

27 Wylie G, Gupta G: Lip-enhancing tattoo reaction resolving with topical tacrolimus. Clin Exp Dermatol 2008;33:505-506. 
28 Fitzpatrick RE, Lupton JR: Successful treatment of treatment resistant laserinduced pigment darkening of a cosmetic tattoo. Lasers Surg Med 2000;27:358361.

29 Mafong EA, Kauvar AN, Geronimus RG: Surgical pearl: removal of cosmetic lipliner tattoo with pulsed carbon dioxide laser. J Am Acad Dermatol 2003;48: 271-272.

30 Ibrahimi OA, Syed Z, Sakomoto FH, et al: Treatment of tattoo allergy with ablative fractional resurfacing: a novel paradigm for tattoo removal. J Am Acad Dermatol 2011;66:111-114.
31 Van der Velden EM, Oostrom CAM, Roddi R, et al: Dermatography with penta-monogalloylglucose as a new treatment for removal of color pigments in the eyebrows. Am J Cosm Surg 1995; 12: 3-9.

32 Chiang JK, Barsky S, Bronson DM: Tretinoin in the removal of eyeliner tattoo. J Am Acad Dermatol 1999;40: 999-1001.

33 Verhaeghe E: Techniques and devices used for tattoo removal; in De Cuyper C, Pérez-Cotapos ML (eds): Dermatologic Complications with Body Art: Tattoos, Piercings and Permanent Make-Up. Berlin, Springer Heidelberg, 2010, pp 91-105.
34 Anderson RR, Geronimus R, Kilmer SL: Cosmetic tattoo ink darkening. A complication of Q-Switched and pulsed-laser treatment. Arch Dermatol 1993;129: 1010-1014.

35 Chang SE, Kim KJ, Choi JH: Areolar cosmetic tattoo ink darkening: a complication of alexandrite laser. Dermatol Surg 2002;28:95-96.

36 Jimenez G, Weiss E, Spencer JM: Multiple color changes following laser therapy of cosmetic tattoos. J Dermatol Surg 2002;28:177-179.

37 Reddy KK, Brauer JA, Bernstein L, et al: Topical perfluorodecalin resolves immediate whitening reactions and allows rapid effective multiple pass treatment of tattoos. Lasers Surg Med 2013;45:76-80. 